\title{
Vinyl Acetate Emission Rates and Explosions in Tank Farms in Dilovasi and Yumurtalik, Turkey: A Case Study
}

\author{
Halil Dertli ${ }^{1}$, Didem Saloglu ${ }^{2 *}$ \\ ${ }^{1}$ Chemical Engineering Department, Chemical and Metallurgical Engineering Faculty, Istanbul Technical University, Istanbul \\ 34730, Turkey \\ ${ }^{2}$ Disaster and Emergency Management Department, Disaster Management Institute, Istanbul Technical University, Istanbul \\ 34730, Turkey
}

Corresponding Author Email: saloglu@itu.edu.tr

https://doi.org/10.18280/ijsse.110609

Received: 6 August 2021

Accepted: 2 November 2021

\section{Keywords:}

ALOHA, emission, explosive chemicals,

TANKS 4.09d, vinyl acetate

\begin{abstract}
The emission estimations for vinyl acetate from storage tanks located in Dilovasi and Yumurtalik, Turkey, were completed by using the US EPA standard regulatory storage tanks emission model (TANKS 4.9b). Total annual emission was determined to be 7,603.15 kg/year for Yumurtalik and 6,057.06 kg/year for Dilovasi. In addition, ALOHA software was used in order to define emergency responses required in the case of vinyl acetate leakage based on different scenarios. According to ALOHA program modelling results, the threat regions occurred were 113 and $236 \mathrm{~m}$ for the red threat region, 299 and $663 \mathrm{~m}$ for the orange threat region, and $790 \mathrm{~m}$ and $2.0 \mathrm{~km}$ for the yellow threat region for vinyl acetate toxic vapour in Dilovasi and Yumurtalik, respectively. The threat regions determined were 10 and $15 \mathrm{~m}$ for the red threat region, $9.14 \mathrm{~m}$ for orange threat region, and 20 and $49 \mathrm{~m}$ for the yellow threat region for modelling of flammable area for the vapour cloud of vinyl acetate in Dilovasi and Yumurtalik, respectively. The amount of thermal radiation was determined to be $10 \mathrm{~kW} / \mathrm{m}^{2}$ at a distance of $9.96 \mathrm{~m}$ from the tanks in both Dilovasi and Yumurtalik during a jet fire.
\end{abstract}

\section{INTRODUCTION}

Specific volatile organic compounds (VOCs) are determined in air today and ambient air concentrations of various VOCs such as acetone, acetonitrile, chloroform, toluene, and vinyl acetate exceed health criteria. The detection of VOCs in the ambient air is related to the decreases in air quality due to the formation of photochemical reactions $[1,2]$.

Air pollutant emission limits are used in many countries, including Turkey. In Turkey, air quality policies and legislation are in force and an air quality management system has been established. Turkey's major storage facilities are located near the Marmara Sea and also the Mediterranean Sea. Organic liquids, monomeric and polymeric compounds, and petroleum-based chemicals used in many countries are imported through both Marmara and Mediterranean Sea ports and stored in the chemical plants and tank farms placed these regions before transportation. Petroleum products and organic compounds such as solvents, monomeric and polymeric chemicals are very critical chemical compounds for economy. In Turkey, tank farms operate using some regulations in order to control of atmospheric emissions. The annual average emissions of VOCs from various organic liquids are investigated using the United States Environmental Protection Agency (US EPA) standard regulatory emission model (TANKS). The API 2518 method of the American Petroleum Institute (API) is one of the most important references for calculation of the annual average emissions of VOCs. The EPA includes all information and calculations regarding the evaporation losses that occur during the storage of organic liquids in the Emission Factors EPA AP-42 document. With the TANKS $4.09 \mathrm{~d}$ software program developed by the EPA, working, breathing losses and total emissions can be calculated for tanks where organic liquids are stored [3, 4].

The secured and protected regions for fire and explosion of VOCs and toxic compounds during an accident is very important. In order to determine safe regions, various software programs such as BREEZE, CHARM, QRA, and ALOHA are used. Areal Location of Hazardous Atmosphere (ALOHA) is a software used for modelling hazards from chemical release, thermal radiation, and vapour cloud explosions [5, 6].

The exposure duration and concentrations of chemicals are used to define the level of exposure of individuals or safety regions in industries and emergency response planning [7]. To examine the toxic effects of the chemical compounds, various parameters and criteria can be used. The most important criteria used in ALOHA is acute exposure guideline levels available in three tiers (AEGL-1, AEGL-2, and AEGL-3). AEGL-3 is the airborne concentration of a chemical above which it is assumed that people around the source may experience death or life-threatening serious health effects. AEGL-2 is the airborne concentration of a chemical above which it is assumed that people may experience irreversible long-lasting health effects. AEGL-1 is the airborne concentration of a chemical above which it is assumed that people may experience discomfort [8].

In this study, a vinyl acetate storage tank located in real tank farms in Dilovası, Kocaeli, Turkey and Yumurtalik, Adana, Turkey was selected as the model. The aim was investigation of the working and breathing losses and annual average 
emissions during storage and handling (filling/discharge) processes of vinyl acetate from storage tanks. In addition, the consequences of leakage from storage tanks containing vinyl acetate were examined using different scenarios in order to define explosion and environmental threats. For the first scenario, vinyl acetate leaks from the storage tank and diffuses without a fire in Dilovası, Kocaeli, Turkey and Yumurtalik, Adana, Turkey. Next, as the second scenario, it was considered that there was a leak from the tank and it burned as a jet fire in Dilovasi and Yumurtalik. As the third scenario, it was simulated that vinyl acetate tanks exploded and gas burned as a fireball in both places. With modelling done in this paper, a profile of vinyl acetate concentration and regions impacted by vinyl acetate vapour can be obtained. The direction and magnitude of the vapour can be predicted, and the potential losses that can arise can be minimized.

Also, the effects of geographic locations and meteorological conditions on emissions, explosions, and environmental threats were defined. The annual average meteorological data for both Dilovası, Kocaeli, Turkey and Yumurtalik, Adana, Turkey were used in order to calculate the emissions. The TANKS $4.09 \mathrm{~d}$ program was used to determine the emissions of vinyl acetate monomer, and the ALOHA program was used to model the scenarios based on leakage from the storage tanks.

There are a number of pollutants such as gas/vapor emissions and chemicals are related to air pollution. These pollutants occur different components, including acids such as sulfuric acid and nitric acid; inorganic compounds such as ammonium sulfate, ammonium nitrate, and sodium chloride; organic chemicals such as vapor of acrylates, polyaromatic hydrocarbons, toluene, and xylene etc. Among organic pollutants, the emission and environmental threats from vinyl acetate monomer selected to be a model component were evaluated in the present paper and it can be safely stated that this study was carried out for the first time in the literature. This paper is a new and pioneering study that will guide both the literature and industrial plants. The work has high originality and novelty.

\section{METHODS}

\subsection{Properties of vinyl acetate monomer}

Vinyl acetate monomer is a colourless liquid with a low flash point and high evaporation. Vinyl acetate, which is insoluble in water, is widely used for polymer synthesis due to its easy polymerization features. The molecular weight of vinyl acetate is $86.09 \mathrm{~g} / \mathrm{mol}$ and density is $937.6 \mathrm{~kg} / \mathrm{m}^{3}$. The vapour pressures are $91 \mathrm{mmHg}, 110 \mathrm{mmHg}$, and $140 \mathrm{mmHg}$ at $20^{\circ} \mathrm{C}, 25^{\circ} \mathrm{C}$, and $30^{\circ} \mathrm{C}$, respectively.

\subsection{TANKS 4.09d software and parameter setting}

Organic vapour emissions are common when highly volatile liquid chemicals are stored in storage tanks. Evaporation losses are basically;

a) Filling/Emptying Loss

b) Breathing Loss

c) Boiling Loss

The breathing and filling/discharge losses are important, and boiling loss is not a common evaporation loss. Filling/discharge loss occurs during the filling of liquid chemicals into the tank. The breathing loss is the vapours released into the atmosphere from the tank breather due to the increase in vapour pressure of the liquid depending on the ambient temperature.

In this study, the emission rates for vinyl acetate from storage tanks located in tank farms in Dilovası, Kocaeli, Turkey and Yumurtalik, Adana, Turkey were calculated using TANKS $4.09 \mathrm{~d}$ software.

Using TANKS 4.09d software, parameters such as chemicals stored in the tank, location of the tank, tank characteristics, and meteorological data were entered into the system when calculating filling, breathing losses and also annual emission rates (Table 1).

Table 1. Characteristics of vinyl acetate storage tank in Dilovas1, Kocaeli, Turkey and Yumurtalik, Adana, Turkey

\begin{tabular}{cc}
\hline Identification & \\
\hline Type of Tank: & Vertical Fixed Roof Tank \\
Description: & Vinyl acetate Storage Tank \\
Tank Dimensions & \\
Shell Height (ft): & 49.00 \\
Diameter (ft): & 49.00 \\
Liquid Height (ft) : & 30.00 \\
Avg. Liquid Height (ft): & 15.00 \\
Volume (gallons): & $423,191.07$ \\
Turnovers: & 4.00 \\
Paint Characteristics & \\
Shell Color/Shade: & White/White \\
Shell Condition & Good \\
Roof Color/Shade: & White/White \\
Roof Condition: & Good \\
Roof Characteristics & \\
Type: & Cone \\
Height (ft) & 0.00 \\
Slope (ft/ft) (Cone Roof) & 0.06 \\
Breather Vent Settings & \\
Vacuum Settings (psig): & -0.03 \\
Pressure Settings (psig) & 0.03 \\
Average Temperature (Avg Atm. Pressure $=14$ psia) \\
Dilovas1, Kocaeli, Turkey \\
Yumurtalik, Adana, Turkey & $24.4^{\circ} \mathrm{C}$ \\
\hline
\end{tabular}

\subsection{Statistical software}

The modelling program used in the present paper was ALOHA 5.4.7, an atmospheric distribution software for analysing releases of hazardous chemical compounds. Based on the parameters using in the program, the ALOHA software draws the toxic effect and explosion limits of vinyl acetate on 2D graphs with different colours. These graphs and colours indicate the danger regions [9]. Characteristics of vinyl acetate storage tanks are shown in Table 2.

In the present work, secured regions and also survival regions were examined for vinyl acetate according to different scenarios using ALOHA. As it is known that in the regions outside the secured regions, people around the threat source can be exposed to toxic vapor of hazardous compounds for up to $1 \mathrm{~h}$ and can experience irreversible health effects. These regions or distances are determined by using AEGLs.

In the present paper, the effects of explosions during vinyl acetate escape from the tanks in two tank farms in Dilovasi and Yumurtalik, Turkey without burning, with burning, and BLEVE of vinyl acetate were modelled using the ALOHA program. The worst possible scenarios were considered in order to decrease the losses for the chemical plants (Scheme $1)$. 
Table 2. Characteristics of vinyl acetate storage tank in Dilovası, Kocaeli, Turkey and Yumurtalik, Adana, Turkey

\begin{tabular}{cc}
\hline Parameter & Unit \\
\hline Component & Vinyl acetate \\
Tank type & Cylindrical \\
Wind speed & $3.9 \mathrm{~m} / \mathrm{s}$ \\
Direction of wind & $\mathrm{SE}$ \\
Relative Humidity & $75 \%$ \\
Ambient temperature of Dilovasi & $19.7^{\circ} \mathrm{C}$ \\
Ambient temperature of Yumurtalik & $24.4^{\circ} \mathrm{C}$ \\
Filling ratio of the tank & $61 \%$
\end{tabular}

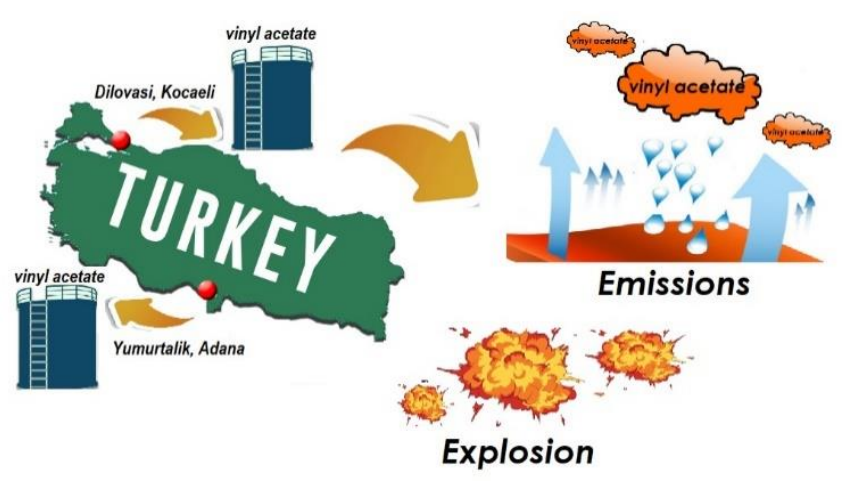

Scheme 1. Mechanism of the paper

The examined vinyl acetate storage tanks were located in Dilovasi and Yumurtalik, Turkey. Latitude and longitude of Dilovasi are $40^{\circ} 46^{\prime} 28^{\prime \prime} \mathrm{N}$ and $29^{\circ} 32^{\prime} 3^{\prime \prime} \mathrm{E}$ and latitude and longitude of Yumurtalik are $36^{\circ} 46^{\prime} 09^{\prime \prime} \mathrm{N}$ and $35^{\circ} 47^{\prime} 49^{\prime \prime} \mathrm{E}$.

The important parameters for ALOHA to model gas leakage from storage tanks are atmospheric data such as temperature and humidity. Temperature has a significant effect on the diffusion of the vinyl acetate cloud and resulting human injury and fatality risk. In this paper, temperature was examined as an important parameter for diffusion of the gas.

This paper was conducted with scenarios as follows:

Scenario 1: Vinyl acetate leaks from the storage tank and diffuses without fire in Dilovasi and Yumurtalik, Turkey;

Scenario 2: Vinyl acetate leaks from the storage tank and burns in the environment as a jet fire in Dilovasi and Yumurtalik, Turkey;

Scenario 3: Vinyl acetate tank explodes and vinyl acetate burns as a fireball (BLEVE) in Dilovasi and Yumurtalik, Turkey.

\section{RESULTS AND DISCUSSION}

\subsection{Emissions of vinyl acetate}

Dilovasi, Kocaeli and Yumurtalik, Adana were used to compare weather data from different sources. There are significant differences between the temperature values for Dilovasi and Yumurtalik used in the TANKS version 4.0.9d software and those from General Directorate of Meteorology (GDM) in Turkey. According to GDM data, the monthly temperature values were determined to be 9.6 and $15.3^{\circ} \mathrm{C} ; 10.5$ and $16.5^{\circ} \mathrm{C} ; 13.2$ and $19.3^{\circ} \mathrm{C} ; 18.5$ and $22.6^{\circ} \mathrm{C} ; 23.2$ and $25.9^{\circ} \mathrm{C} ; 27.4$ and $29.2^{\circ} \mathrm{C} ; 29.4$ and $31.7^{\circ} \mathrm{C} ; 26$ and $33.1^{\circ} \mathrm{C} ; 20.9$ and $31.8^{\circ} \mathrm{C} ; 16.4$ and $28.3^{\circ} \mathrm{C} ; 11.7$ and $17.2^{\circ} \mathrm{C}$ in Dilovasi and Yumurtalik, respectively. In addition, Table 1 shows the differences in average temperature values for Dilovasi and
Yumurtalik. The average temperature values were determined to be 19.7 and $24.4^{\circ} \mathrm{C}$ for Dilovasi and Yumurtalik, respectively. It is predicted that the temperature difference between Dilovasi and Yumurtalik causes significant woking loss, breathing loss, and total annual emissions.

These values were used in TANKS 4.09d and ALOHA software. Table 3 compares working loss, breathing loss, and total annual emissions from storage tanks in Dilovasi and Yumurtalik.

Table 3. Vinyl acetate emissions

\begin{tabular}{cccc}
\hline & \multicolumn{3}{c}{ Losses (kg/year) } \\
\hline Component & Working & Breathing & Total Emissions \\
\hline Vinyl acetate I & $2,261.32$ & $3,796.05$ & $6,057.06$ \\
Vinyl acetate II & $2,888.78$ & $4,714.37$ & $7,603.15$ \\
\hline *I: Dilovasi, Kocaeli, Turkey and II: Yumurtalik, & Adana, Turkey
\end{tabular}

Examination of Table 3 reveals significantly higher vinyl acetate emission from the storage tank in Yumurtalik compared to Dilovasi. The emissions of vinyl acetate were determined to be $2,888.78 \mathrm{~kg} /$ year and 4,714.37 kg/year during working and breathing from the storage tank in Yumurtalik, respectively. Also, the total emissions of vinyl acetate were calculated to be 7,603.15 kg/year for Yumurtalik and 6,057.06 kg/year for Dilovasi. When working and breathing losses were determined as 2,261.31 and 3,796.05 $\mathrm{kg} /$ year in Dilovasi, the same losses were calculated to be 2,888.87 and 4,714.34 kg/year in Yumurtalik, respectively. The working and breathing losses in Dilovasi were lower in comparison to Yumurtalik. Depending on location, the emission values from the storage tank in Yumurtalik was nearly 1.26 times higher than that of the storage tank in Dilovasi. The observed differences in working loss, breathing loss, and annual average emissions are related to temperature at each location. This effect is more significant for breathing loses, which are extremely effected on temperature. Yumurtalik region has higher temperatures in all months compared to Dilovasi, so also evaporation of the liquid chemicals in tanks here are higher than that of Dilovasi.

\subsection{Scenario 1: Vinyl acetate leaks from the storage tank and diffuses without fire in Dilovasi and Yumurtalik}

\subsubsection{Modelling of the toxic vapour cloud of vinyl acetate}

Vapour cloud explosions are capable of creating great impact on the surroundings. Vapour cloud explosions produce pressure waves. The effect of vapour cloud explosion depends on the peak incident overpressure due to pressure waves and the duration of the maximum overpressure [10].

If the flammable vapor cloud is ignited, it can explode, producing a blast wave which can cause major destruction at a large distance. The results of a vapour cloud explosions are devastating, with nearly total destruction at the center of the event and damage reducing as a distance from the center. Pressure impulse within the vapor cloud area are the highest. Outside the vapor cloud overpressures diminish rapidly with distance, but can be sufficient to result in structural damage over $300 \mathrm{~m}$ away. Complete damage is determined within the perimeter of the vapor cloud, and the range of the 10 psi over pressure. The glass shattering and window frame damage can occur at as low as $0.5 \mathrm{psi}$, and collapse of structures at as little as 2 psi. At pressures above 10 psi, damage can be very dangerous. In addition to structural damages, serious toxic gas emissions can occur as a result of vapor cloud explosions. 
Serious health problems may be observed depending on the amount of toxic gas inhaled.

In the scenario 1, vinyl acetate was diffused by leakage from a rectangular opening with 3 inches length and 0.5 inches width and 1 foot from the tank bottom. The area of toxic threat region, flammable area of vapour cloud, and overpressure (blast force) from vapour cloud explosion were simulated for different locations of Dilovasi and Yumurtalik.

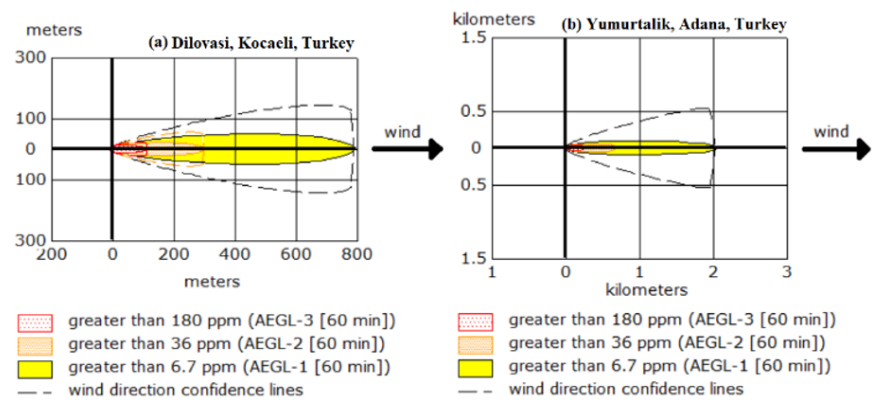

Figure 1. Graphical modelling of the toxic vapour cloud of vinyl acetate

The consequences of graphic modelling of toxic threat regions around the storage tank in Dilovasi are shown in Figure 1(a). Figure 1(a) displays the toxic threat regions with a maximum distance of $790 \mathrm{~m}$. In this scenario, the threat regions occurred were $113 \mathrm{~m}, 299 \mathrm{~m}$, and $790 \mathrm{~m}$ for the red, orange, and yellow threat regions, respectively for vinyl acetate toxic vapour. Based on the explanation of AEGLs, the red region exposure is $180 \mathrm{ppm}$ for 1 hour and cause health effects resulting in death during accidental release. The risk in the orange threat region (exposure of $36 \mathrm{ppm}$ for 1 hour) can be defined to be long-lasting health effects. In addition, the risk in the yellow threat region (exposure of $6.7 \mathrm{ppm}$ for 1 hour) can be mentioned to be irritation effects. It can be safely stated that in the case of the vinyl acetate concentration was higher than $180 \mathrm{ppm}$ near the storage tank placed in Dilovasi, which was described to be AEGL-3 and there was risk of death and vital threat to people in Dilovasi

Figure 1(b) indicates the threat regions were $236 \mathrm{~m}, 663 \mathrm{~m}$, and $2.0 \mathrm{~km}$ for the red, orange, and yellow threat regions, respectively in Yumurtalik. As can be seen from Table 1, the ambient temperature in Dilovasi is nearly $5^{\circ} \mathrm{C}$ lower than Yumurtalik. Therefore, as can be seen from Figure 1, when temperature increases, the rate of diffusion of vinyl acetate increases, and toxic threat region of vinyl acetate changes. According to modelling results in this paper, the red threat region in Yumurtalik was calculated to be nearly 0.5-times the red region in Dilovasi. This clearly shows that the temperature increases the toxic threat regions. It can be safely stated that when temperature increased evaporation of the liquids boosted significantly and this phenomenon resulted in increasing of the threats regions.

\subsubsection{Modelling of flammable area of vapour cloud of vinyl} acetate

The purpose of the $2^{\text {nd }}$ scenario was determination of the flammable area of vapour cloud of vinyl acetate released accidentally in Dilovasi and Yumurtalik [11]. In this scenario, threat regions were not drawn because effects of near-field patchiness make dispersion predictions less reliable for short distances. For the red and orange regions, the vinyl acetate concentrations were higher than $15,600 \mathrm{ppm}$ and 2,600 ppm which fit to the lower explosive limit (LEL). The threat regions were determined to be $10 \mathrm{~m}, 9.4 \mathrm{~m}$, and $20 \mathrm{~m}$ for the red, orange, and yellow threat regions, respectively for the flammable area of the vapour cloud of vinyl acetate in Dilovasi. The red region represents fire risk and everything closer than $10 \mathrm{~m}$ from the source can burn, and also flame pockets occurred in Dilovasi. The orange region was calculated as $9.14 \mathrm{~m}$ where concentration measured to be $26,000 \mathrm{ppm}$. At a distance of $20 \mathrm{~m}$ from the threat source, the concentration equals $10 \%$ of the lower explosive limit $(10 \%$ LEL) of vinyl acetate and the concentration of vinyl acetate was $2,600 \mathrm{ppm}$. The yellow region was determined to be $20 \mathrm{~m}$ where the concentration was $10 \%$ of LEL. The red threat region was determined to be $15 \mathrm{~m}$, orange threat region was found to be $9.14 \mathrm{~m}$ and the yellow threat region was shown to be $49 \mathrm{~m}$ for the simulation of flammable area for the vapour cloud of vinyl acetate in Yumurtalik. With complete leakage of vinyl acetate, if there is any threat for explosion within a distance of $15 \mathrm{~m}$ from the tank explosion will occur in Yumurtalik.

The results showed that concentration of $15,600 \mathrm{ppm}$ vinyl acetate cause severe burns to skin. Comparing results from threat regions for the toxic vapour cloud of vinyl acetate in Dilovasi and Yumurtalik, the effect of temperature can be clearly seen to have the same trend for flammable area of vapour cloud of vinyl acetate. The red and yellow threat regions increased significantly as temperatures increased. The high temperature in Yumurtalik causes vinyl acetate evaporation with a high evaporation rate. Increasing evaporation enhances the amount of vapor cloud. Therefore, the explosion becomes more effective and the explosion causes higher threat regions. It is clear that when the explosion is severe, the ambient temperature will also be high.

\subsubsection{Modelling the explosion area for the vapour cloud of vinyl acetate}

Leakage due to a small opening was assumed for the tank vapour cloud blasts. The rectangular opening was considered in this case. The area for the opening was taken as 3 inches length and 0.5 inches width. Modelling results indicated that the pressure caused by the explosion of vinyl acetate vapour cannot be simulated for leakage from a storage tank in Dilovasi. Overpressure or blast force from the vapour cloud explosion of vinyl acetate in Dilovasi is not shown, and also all parts of the vinyl acetate cloud were above the LEL at any time. Therefore, explosion did not occur and toxic levels of concern were not determined.

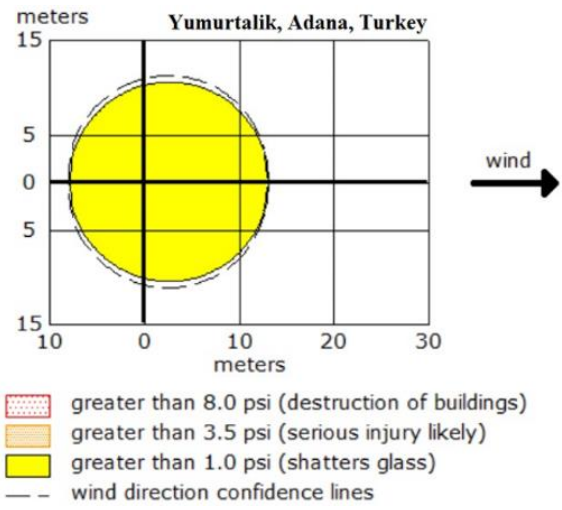

Figure 2. Graphical modelling of explosion area of vapour cloud of vinyl acetate 
In addition, graphical modelling results for the pressure wave caused by the explosion of vinyl acetate vapour is shown in Figure 2.

The red region indicates 8 psi which was never exceeded and so was not drawn for vinyl acetate leakage from a storage tank in Yumurtalik. The orange region was less than $10 \mathrm{~m}$ with an overpressure of $3.5 \mathrm{psi}$ in Yumurtalik. The orange region was susceptible to triggering of a fire. The yellow region was $13 \mathrm{~m}$ with an overpressure of $1.0 \mathrm{psi}$. The yellow region had dangerous effects such as shattering of glass windows and demolition of houses.

\subsection{Scenario 2: Vinyl acetate leaks from the storage tank and burns in the environment as a jet fire}

A jet fire is a fire that may persist for a long time, which is why it poses a significant threat due to the effects of heat radiation. Jet fire is especially dangerous when the damaged tank spontaneously heats up or when the fire is directed at an adjacent tank. Jet fire can happen due to the release of flammable liquids confined or spread in the form of a liquid jet. After catching fire due to external forces, this burns as a jet and radiates heat.

Modelling results for thermal radiation caused by Scenario 2 at various distances from the vinyl acetate storage tanks in Dilovasi and Yumurtalik are shown in Figure 3.

In case of jet fire, thermal radiation was determined to be 10 $\mathrm{kW} / \mathrm{m}^{2}$ at a distance of $9.96 \mathrm{~m}$ from the tanks in both Dilovasi and Yumurtalik. It causes death within 1 hour. Up to distances of $12 \mathrm{~m}$ from the tank in Yumurtalik and $10 \mathrm{~m}$ from the tank in Dilovasi, thermal radiation was calculated to be $5 \mathrm{~kW} / \mathrm{m}^{2}$ and it led to second-degree burns. The amount of radiation was $2 \mathrm{~kW} / \mathrm{m}^{2}$ at a distance of $16 \mathrm{~m}$ from the vinyl acetate storage tanks in both Dilovasi and Yumurtalik and the radiation effect can cause pain (Figure $3 \mathrm{a} \& \mathrm{~b}$ ). Maximum burn rate was determined to be $48.5 \mathrm{~kg} / \mathrm{min}$ in both Dilovasi and Yumurtalik and total burnt amount was found to be $2843 \mathrm{~kg}$ in Dilovasi and $2851 \mathrm{~kg}$ in Yumurtalik. The vinyl acetate puddle spread to a diameter of $4.6 \mathrm{~m}$ in both Dilovasi and Yumurtalik (Figure 3(c)).

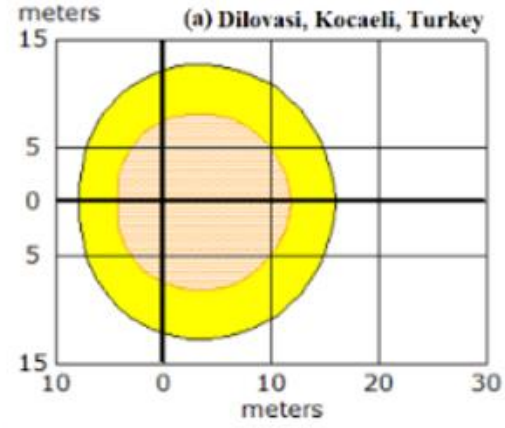

greater than $10.0 \mathrm{~kW} /(\mathrm{sq} \mathrm{m})$ greater than $5.0 \mathrm{~kW} /(\mathrm{sq} \mathrm{m})$ greater than $2.0 \mathrm{~kW} /(\mathrm{sq} \mathrm{m}$ )

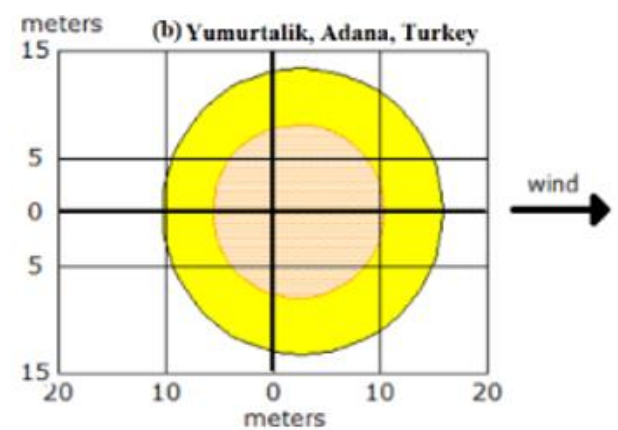

greater than $10.0 \mathrm{~kW} /(\mathrm{sq} \mathrm{m})$ greater than $5.0 \mathrm{~kW} /(\mathrm{sq} \mathrm{m})$ greater than $2.0 \mathrm{~kW} /(\mathrm{sq} \mathrm{m})$

kilograms/minute

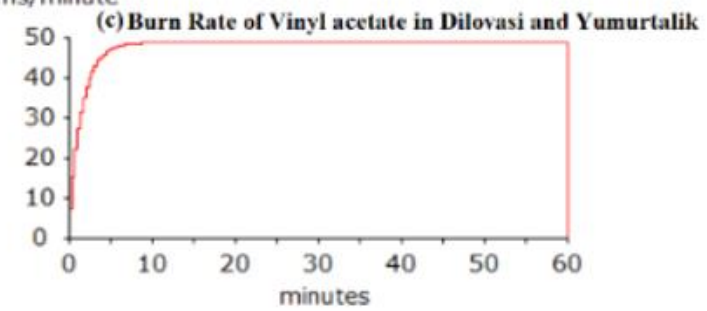

Figure 3. Graphical modelling of thermal radiation of vinyl acetate

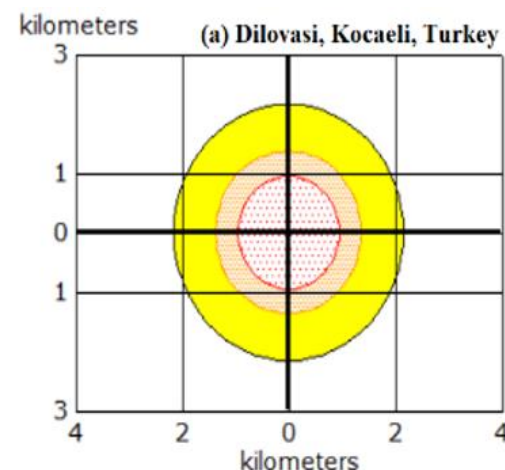

greater than $10.0 \mathrm{~kW} /(\mathrm{sq} \mathrm{m})$ greater than $5.0 \mathrm{~kW} /(\mathrm{sq} \mathrm{m})$ greater than $2.0 \mathrm{~kW} /(\mathrm{sq} \mathrm{m})$
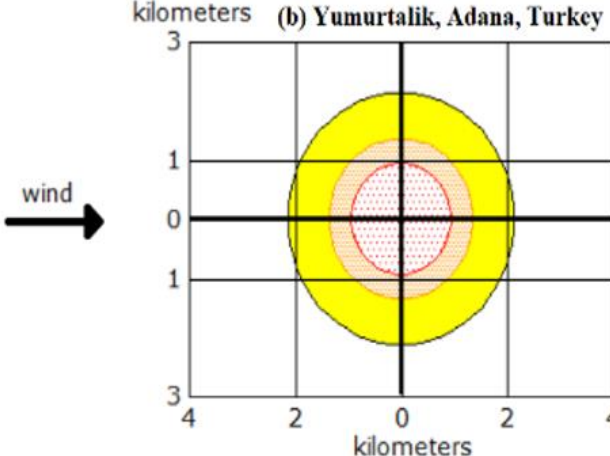

greater than $10.0 \mathrm{~kW} /(\mathrm{sq} \mathrm{m})$ greater than $5.0 \mathrm{~kW} /(\mathrm{sq} \mathrm{m})$ greater than $2.0 \mathrm{~kW} /(\mathrm{sq} \mathrm{m})$

Figure 4. Graphical modelling of boiling liquid expanding vapour explosion (BLEVE) of vinyl acetate 


\subsection{Scenario 3: Vinyl acetate tank explodes and vinyl acetate burns as a fireball (Boiling Liquid Expanding Vapour Explosion- BLEVE)}

BLEVE is a physical explosion which lasts for a few seconds, and may cause an accident with very high intensity. If there is a flammable substance in the tank, the gas cloud formed after the explosion may ignite to form a spherical fire [12].

Figure 4 shows burning of vinyl acetate as a jet fire and the red, orange, and yellow areas represented the damaged regions on the plot. The burning of vinyl acetate as a jet fire was simulated on the map in three different regions. The first region is very dangerous because the thermal radiation is 10 $\mathrm{kW} / \mathrm{m}^{2}$ and can result in death in 1 hour. The second region is also dangerous as thermal radiation is $5 \mathrm{~kW} / \mathrm{m}^{2}$ and can result in $2^{\text {nd }}$ degree burns. The third region is less dangerous as thermal radiation is $2 \mathrm{~kW} / \mathrm{m}^{2}$ and results in pain. The red threat regions show $10 \mathrm{~kW} / \mathrm{m}^{2}$ thermal radiation extended 933 and $951 \mathrm{~m}$ in all directions and was potentially lethal within 1 hour which means it will cause the loss of lives in these areas in Dilovasi and Yumurtalik, respectively.

The orange threat region showing $5 \mathrm{~kW} / \mathrm{m}^{2}$ thermal radiation extended $1.3 \mathrm{~km}$ and $1.4 \mathrm{~km}$ in Dilovasi and Yumurtalik, respectively. The yellow threat region shows 2 $\mathrm{kW} / \mathrm{m}^{2}$ thermal radiation extended $2.1 \mathrm{~km}$ and $2.2 \mathrm{~km}$ in Dilovasi and Yumurtalik, respectively.

\section{CONCLUSION}

The results of the present study contribute to the scientific literature in two main ways. First, by determining the emission rates of vinyl acetate monomer in storage tanks at the Dilovasi and Yumurtalik tank farms and examining the effect of meteorological factors on emission values. Second, the danger regions for vinyl acetate were modelled and detected using different explosion and hazard scenarios. According to the results, working and breathing losses and the total rate of the vinyl acetate emitted from the storage tanks in Dilovasi and Yumurtalik facilities were determined. In addition, based on the computer simulations performed using the ALOHA program, ranges of danger regions for selected emergency scenarios were examined. After performing the simulation, the ALOHA application allows modelling of the extent of hazardous areas during an accidental release of vinyl acetate. The results of the study applied different scenarios to calculate the distance of the threat regions according to vinyl acetate dispersion models.

\section{REFERENCES}

[1] Zhou, J., You, Y., Bai, Z., Hu, Y., Zhang, J., Zhang, N. (2011). Health risk assessment of personal inhalation exposure to volatile organic compounds in Tianjin. Science of the Total Environment, 409(3): 452-459. https://doi.org/10.1016/j.scitotenv.2010.10.022

[2] Zhao, N., Wang, G., Li, G., Lang, J. (2021). Trends in air pollutant concentrations and the impact of meteorology in Shandong Province Coastal China, during 2013-2019. Aerosol and Air Quality Research, 21(6): 1-16. https://doi.org/10.4209/aaqr.200545

[3] Truong, S.C., Lee, M.I., Kim, G., Kim, D., Park, J.H, Choi, S.D. (2016). Accidental benzene release risk assessment in an urban area using an atmospheric dispersion model. Atmospheric Environment, 144: 146159. https://doi.org/10.1016/j.atmosenv.2016.08.075

[4] Karbasi, A., Khoramnezhadian, S., Asemi Zavareh, S.A., Pejman Sani, G. (2018). Determination of the emission rate and modeling of benzene dispersion due to surface evaporation from an oil pit. Journal of Air Pollution and Health, 3(3): 155-166.

[5] Terzioglu, L., Iskender, H. (2021). Modeling the consequences of gas leakage and explosion fire in liquefied petroleum gas storage tank in Istanbul Technical University, Maslak Campus. Process Safety Progress, 1-8. https://doi.org/10.1002/prs.12263

[6] Sharma, R.K., Gurjar, B.R., Wate, S.R., Ghuge, S.P., Agrawal, R. (2013). Assessment of an accidental vapor cloud explosion: Lessons from the Indian Oil Corporation Ltd. accident at Jaipur, India. Journal of Loss Prevention in the Process Industry, 26(1): 82-90. https://doi.org/10.1016/j.jlp.2012.09.009

[7] Atabi, F., Ghorbani, R., Jabbari, M. (2017). Assessment of safe distance for five toxic materials commonly in the accidents of chemical road transportation using ALOHA and PHAST software and CEI index (Case Study: Tehran-Qazvin Highway) Iran. Iran Occupational Health, 14(4): 35-42

[8] Bariha, N., Mishra, I., Srivastava, W. (2016). Fire and explosion hazard analysis during surface transport of liquefied petroleum gas (LPG): A case study of LPG truck tanker accident in Kannur, Kerala, India. Journal of Loss Prevention in the Process Industry, 40: 449-460. https://doi.org/10.1016/j.jlp.2016.01.020

[9] Iskender, H. (2021). Risk assessment for an acetone storage tank in a chemical plant in: Simulation of dangerous scenarios. Process Safety Progress, 1-6. https://doi.org/10.1002/prs.12252

[10] Bhisham, K., Dhurandher, A., Ravi, K., Amit, D. (2015). Impact assessment of thermal radiation hazard from LPG fireball. Procedia Environmental Science, 11: 499-506. https://doi.org/10.1016/j.proeps.2015.06.050

[11] Naderpour, M., Khakzad, N. (2018). Texas LPG fire: Domino effects triggered by natural hazards. Process Safety and Environmental Protection, 116: 354-364. https://doi.org/10.1016/j.psep.2018.03.008

[12] Lee, T.S., Sung, J.Y., Park, D.J. (2012). Experimental investigations on the deflagration explosion characteristics of different DME-LPG mixtures. Fire Safety Journal, $\quad$ 49: 62-66. https://doi.org/10.1016/j.firesaf.2011.12.003 